\title{
Linking tyrosine kinase inhibitor-mediated inflammation with normal epithelial cell homeostasis and tumor therapeutic responses
}

\author{
Natalia J. Gurule, Lynn E. Heasley \\ Department of Craniofacial Biology, University of Colorado Anschutz Medical Campus, Aurora, CO 80045, USA.
}

Correspondence to: Natalia J. Gurule, Department of Craniofacial Biology, University of Colorado Anschutz Medical Campus, 12801 E. 17th Ave., Aurora, CO 80045, USA. E-mail: natalia.gurule@ucdenver.edu

How to cite this article: Gurule NJ, Heasley LE. Linking tyrosine kinase inhibitor-mediated inflammation with normal epithelial cell homeostasis and tumor therapeutic responses. Cancer Drug Resist 2018;1:118-25.

http://dx.doi.org/10.20517/cdr.2018.12

Received: 6 Jul 2018 First Decision: 1 Aug 2018 Revised: 16 Aug 2018 Accepted: 20 Aug 2018 Published: 19 Sep 2018

Science Editors: Elisa Giovannetti, Jose Antonio Rodriguez Copy Editor: Yuan-Li Wang Production Editor: Cai-Hong Wang

\begin{abstract}
Receptor tyrosine kinases (RTKs) bearing oncogenic mutations in EGFR, ALK and ROS1 occur in a significant subset of lung adenocarcinomas. Tyrosine kinase inhibitors (TKIs) targeting tumor cells dependent on these oncogenic RTKs yield tumor shrinkage, but also a variety of adverse events. Skin toxicities, hematological deficiencies, nausea, vomiting, diarrhea, and headache are among the most common, with more acute and often fatal side effects such as liver failure and interstitial lung disease occurring less frequently. In normal epithelia, RTKs regulate tissue homeostasis. For example, EGFR maintains keratinocyte homeostasis while MET regulates processes associated with tissue remodeling. Previous studies suggest that the acneiform rash occurring in response to EGFR inhibition is a part of an inflammatory response driven by pronounced cytokine and chemokine release and recruitment of distinct immune cell populations. Mechanistically, blockade of EGFR causes a Type I interferon response within keratinocytes and in carcinoma cells driven by this RTK. This innate immune response within the tumor microenvironment (TME) involves increased antigen presentation and effector $T$ cell recruitment that may participate in therapy response. This TKI-mediated release of inflammatory suppression represents a novel tumor cell vulnerability that may be exploited by combining TKIs with immune-oncology agents that rely on T-cell inflammation for efficacy. However, early clinical data indicate that combination therapies enhance the frequency and magnitude of the more acute adverse events, especially pneumonitis, hepatitis, and pulmonary fibrosis. Further preclinical studies to understand TKI mediated inflammation and crosstalk between normal epithelial cells, cancer cells, and the TME are necessary to improve treatment regimens for patients with RTK-driven carcinomas.
\end{abstract}

Keywords: Tyrosine kinase inhibitor, receptor tyrosine kinase, interferon, inflammation, tumor microenvironment, epithelial tissue homeostasis

Cc) (i) The Author(s) 2018. Open Access This article is licensed under a Creative Commons Attribution 4.0 International License (https://creativecommons.org/licenses/by/4.0/), which permits unrestricted use sharing, adaptation, distribution and reproduction in any medium or format, for any purpose, even commercially, as long as you give appropriate credit to the original author(s) and the source, provide a link to the Creative Commons license, and indicate if changes were made.

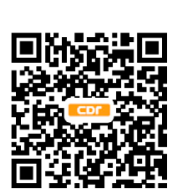




\section{ONCOGENIC RECEPTOR TYROSINE KINASES AS TARGETS FOR PRECISION MEDICINE}

Malignancies of epithelial tissues account for 80 to 90 percent of all cancer cases, making carcinomas the most common histological type of cancer ${ }^{[1]}$. Activating mutations in receptor tyrosine kinases (RTKs) and their associated downstream signal pathways function as oncogene drivers in many solid tumor types. Lung adenocarcinomas (LUADs) serve as an example of a carcinoma arising from distinct pulmonary epithelial cells that harbor many diverse oncogenic RTKs including EGFR, ALK, MET, and ROS1 ${ }^{[2]}$. Moreover, specific tyrosine kinase inhibitors (TKIs) are now routinely deployed as first-line therapies in patients with lung tumors presenting with these oncogenic RTKs. Examples of these TKIs include gefitinib or osimertinib for EGFR, and crizotinib or ceritinib for ALK, ROS1 and MET. Cetuximab, a monoclonal antibody against EGFR is also used to treat patients with head and neck squamous carcinoma (HNSCC), which often overexpress $\mathrm{EGFR}^{[3]}$. Thus, these oncogene targeted agents have proven efficacious for inducing tumor regression as firstline therapies, although complete responses are rare and emergence of acquired resistance is universal ${ }^{[4]}$.

Although TKIs are less toxic than traditional cytotoxic drugs, their use is still associated with various adverse effects including skin toxicity, hematological deficiencies, nausea, vomiting, diarrhea, and headaches being the most common side effects. Skin toxicities are very frequent, occurring in $49 \%-95 \%$ of patients treated with EGFR inhibitors, and $16 \%$ of patients treated with ALK/c-MET inhibitors ${ }^{[5-7]}$. More acute and often fatal side effects such as liver toxicity and forms of interstitial lung disease (ILD) occur at a lower frequency in cancer patients treated with the TKIs gefitinib, erlotinib, and crizotinib ${ }^{[8,9]}$. ILDs such as pneumonitis and pulmonary fibrosis occur at frequencies of $<1 \%$ and $1.6 \%$ respectively with EGFR inhibitors and ALK inhibitors ${ }^{[5,10]}$.

The role of EGFR in regulating cellular proliferation, survival, and differentiation during development, tissue homeostasis, and carcinogenesis is well established. EGFR is expressed in a variety of normal epithelial tissues including $\operatorname{skin}^{[11]}$. Within the epidermis, EGFR is most prominently expressed in proliferating basal and suprabasal keratinocytes. In keratinocytes, EGFR signaling sustains proliferation and migration and delays apoptosis in suprabasal keratinocytes that are no longer attached to matrix ${ }^{[12-14]}$. In addition to normal keratinocyte dependent skin homeostasis, EGFR signaling functions in the protective response triggered by epithelial cells during wound healing or during defense against microorganisms that cause skin infections. EGFR is also highly expressed in alveolar type II epithelial cells in the lung ${ }^{[15,16]}$. The MET tyrosine kinase receptor and its ligand HGF have well characterized functions in tissue remodeling via regulating cellular processes such as proliferation, apoptosis, morphogenic differentiation, motility, invasion and angiogenesis. MET is expressed on the surface of epithelial cells in the liver, pancreas, prostate, kidney, and lung ${ }^{[17]}$ and is essential for both embryonic liver development and liver regeneration after injury ${ }^{[18-20]}$.

\section{RECEPTOR TKIS DE-REPRESS INNATE IMMUNE RESPONSES IN TUMOR CELLS AND NORMAL}

\section{EPITHELIAL CELLS}

As previously mentioned, acneiform rash is an established side effect of both small molecule and antibody-based inhibitors of EGFR ${ }^{[21]}$, typically presents within the first two weeks of administration of EGFR inhibitor and is a positive predictor of response to therapy. Not only is there a positive correlation between rash and therapeutic response of the tumor, but progression free survival and overall survival are also positively correlated with presence of these skin toxicities ${ }^{[22-25]}$. There are three main contributors to EGFR inhibitor induced skin toxicity; damage to the epithelial barrier, loss of antimicrobial mechanisms, and extensive release of inflammatory chemokines and cytokines. For the purpose of this article, we will focus on TKI mediated chemokine and cytokine release. The mechanisms contributing to damage to the integrity of the epithelial barrier and antimicrobial defense loss has been previously reviewed ${ }^{[26]}$. The EGFR inhibitor-induced inflammation is characterized by robust release of chemokines and cytokines that recruit and activate distinct immune cell populations including dendritic cells, macrophages, granulocytes, mast cells and $\mathrm{T}$ cells ${ }^{[1,13,27]}$. Mechanistically, Pastore and colleagues have demonstrated that this inflammatory phenotype is largely driven by a type I interferon (IFN) response 


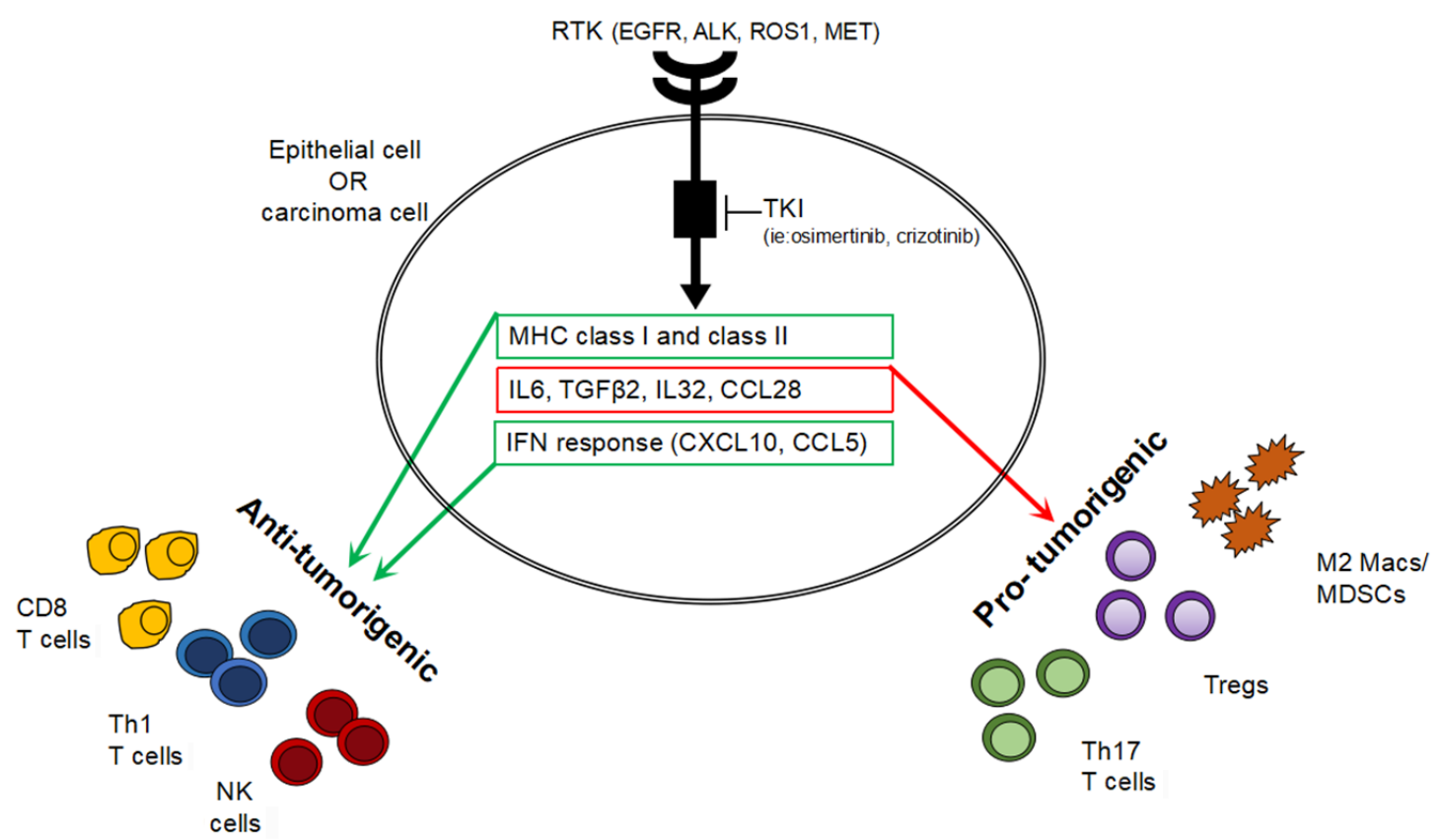

Figure 1. Induction of an inflammatory phenotype in response to RTK inhibition in normal epithelia and carcinomas. RTK: receptor tyrosine kinase; NK: natural killer

that occurs in keratinocytes following inhibition of EGFR signaling. A type I IFN response has classically been viewed as an inducer of cell- intrinsic antimicrobial signals that repress the spread of infectious agents, particularly viral pathogens, to neighboring cells ${ }^{[28]}$. Type I IFNs also function to modulate innate immune responses that occur upon infection to engage the adaptive immune system through increased expression of the chemokines, CXCL10, CXCL9, CCL2, and CCL5. Studies performed by Mascia et al. ${ }^{[13]}$ using primary human keratinocytes treated in vitro with erlotinib demonstrate an increase in secretion of CCL27, CXCL14, CCL2 and CCL5. Furthermore, immunohistochemistry (IHC) staining performed on cutaneous lesions from patients treated with erlotinib show an increase in markers for macrophages, natural killer (NK) cells, dendritic cells, and both $\mathrm{CD} 4$ and CD8 positive T cells. Similar inflammatory responses are seen in response to the EGFR TKI, gefitinib and the monoclonal antibody cetuximab. Furthermore, in vivo studies where EGFR has been genetically ablated in murine epidermal cells demonstrates an increase in transcripts for CCL2, CCL5 and CCL22 in the skin and circulation within their first week of life, prior to presence of immune cell populations ${ }^{[12,13]}$.

The precise cellular and molecular mechanisms underlying the TKI mediated induction of an inflammatory phenotype and patient response to therapy remains ill-defined, but we propose that this response originates within oncogenic tumor cells and alters the immune landscape of the tumor microenvironment (TME). Our recent studies indicate that the TKI mediated inflammatory phenotype is not restricted to normal epithelial cells, but also occurs in lung carcinoma cells in response to TKI treatment ${ }^{[34]}$. We observe that oncogenic EGFR and ALK cause a suppression of an IFN like inflammatory response, as evidenced by marked induction of both pro-tumorigenic (IL6, TGFB2) and anti-tumorigenic (CXCL10) chemokines and cytokines following treatment of lung cancer cell lines with oncogene specific TKIs [Figure 1]. We also detect induction of these genes in on-treatment patient lung tumor samples. This IFN-like inflammatory response is not unique to EGFR inhibitors as it also occurs in response to crizotinib in EML4-ALK positive lung cancer cell line models. Thus, the literature and our preliminary data support a hypothesis that RTKs actively suppress inflammatory pathways, both in settings of normal tissue homeostasis and in cancer cells. Moreover, oncogene targeted agents may lead to recruitment of innate and adaptive immune cells for participation in the tumor response. 
Treatment with oncogene specific TKIs induces tumor/epithelial cell-autonomous expression of MHC class I and II involved in antigen presentation, CXCL10 involved in effector immune cell recruitment and IL6, TGFB2 and CCL28 which recruit and activate immune suppressive cell types. This inflammatory phenotype represents a normal physiological response in normal epithelial cells and is retained in carcinoma cells providing a link between normal epithelial cell homeostasis and tumor therapeutic response. These proteins and factors are postulated to instruct both pro- and/or anti- tumorigenic immune cells and contribute to the degree of therapeutic response observed in patients with lung cancer driven by oncogenic RTKs.

In addition to engaging in paracrine communication with the TME through activation of an IFN like response, EGFR inhibitors also have the potential to influence immune responses by modulating MHC expression and antigen presentation. In the context of cancer immunology, MHC molecules govern interactions between tumor cells and CD4 and CD8 positive T cells by functioning as antigen presenting machinery for tumor specific antigens. Pollack et al. ${ }^{[29]}$, Kersh et al.$^{[30]}$ and Pollack ${ }^{[31]}$ demonstrated that treatment with multiple EGFR TKIs and cetuximab enhanced the induction of MHCI and MHCII seen when primary keratinocytes and malignant keratinocyte A431 cells were treated with IFN $\gamma$. Skin biopsies from patients treated with and EGFR inhibitor also demonstrated an increase in epidermal MHCI expression. This response was also observed with erlotinib, cetuximab, and the pan-ErbB inhibitor, dacomitinib, in head and neck cancer cell $\operatorname{lines}^{[32,33]}$. Interestingly, this EGFR inhibitor-mediated induction of MHCI was observed in the absence of IFN $\gamma$. These findings support a role for EGFR not only in immune surveillance via immune cell recruitment, but also in immunoediting through increased antigen presentation.

\section{ROLE OF THE TUMOR IMMUNE MICROENVIRONMENT IN DICTATING IMMUNOTHERAPY RESPONSE}

Inflammation characterized by expression of genes that drive immune cell infiltration has recently come to light as being important in response to immune-oncology (IO) drugs that inhibit the PD1-PDL1 immune checkpoint. Clinical benefit has been observed in carcinomas of the lung, head and neck, and skin, however patients who are never smokers (i.e., ALK, ROS, and RET positive lung tumors) or whose tumors express mutant EGFR, whether PD-L1 positive or negative, have not experienced benefit ${ }^{[35]}$. In ALK and EGFR mutant lung cancer patients whose tumors tested high for PD-L1, overall response rate following durvalumab treatment was only $0 \%-14 \%$. These data suggest that some patients within these cancer subgroups may exhibit innate resistance to immunotherapy agents, despite the presence of PD-L1 positivity. To this end, Gajewski and colleagues have proposed that T cell inflammation within the TME serves as a superior predictive marker of sensitivity to immunotherapy, and that tumors with scant $\mathrm{T}$ cell inflammation exhibit poor responses consistent with innate resistance ${ }^{[36-38]}$. In this context, $\mathrm{T}$ cell inflammation is associated with activation of IFN response pathways. As support of this, Ayers et al. ${ }^{[39]}$ and colleagues report an IFN $\gamma$ signature that predicts response to anti-PD1 better than PD-L1 positivity, alone, across multiple cancers.

Despite some evidence for modestly increased response rates in early trials with combinations of TKIs and IO agents in lung cancer patients, there are tolerability and safety challenges arising as a result of severe toxicities ${ }^{[40]}$. Based on the results of recent trials, combining these two treatment modalities is predicted to yield enhanced frequency and grade of on-target side effects. In support of this, the TATTON trial [Table 1], a multi-arm phase Ib trial investigating osimertinib in combination with durvalumab in patients with EGFR mutant NSCLC, reported an increase in ILD with the combination compared to either drug alone ${ }^{[41]}$. Likewise, the phase I CheckMate012 trial with erlotinib in combination with nivolumab in EGFR mutant patients reports incidences of discontinued treatment due to pneumonitis as well as hepatic toxicities ${ }^{[42,43]}$. Furthermore, the CheckMate370 trial, a single arm study to evaluate the safety of nivolumab in combination with crizotinib in patients with ALK positive NSCLC, also reported incidence of severe and fatal hepatic toxicities ${ }^{[4]}$. Collectively, the early results from these trials indicate that combining TKIs with 
Table 1. Combination therapy trials of TKIs and immunotherapy in lung cancer

\begin{tabular}{lllll}
\hline Study & \multicolumn{1}{c}{ Identifier } & \multicolumn{1}{c}{ Type } & Oncogene & \multicolumn{1}{c}{ Therapy } \\
\hline TATTON & NCT02143466 & $\begin{array}{l}\text { Multi-arm phase } \\
\text { lb }\end{array}$ & EGFR & $\begin{array}{l}\text { Osimertinib + durvalumab, } \\
\text { savolitinib, selumetinib } \\
\text { CheckMate012 }\end{array}$ \\
NCT01454102 & Phase I & EGFR & $\begin{array}{l}\text { Nivolumab+ erlotinib, chemotherapy, Active, not recruiting } \\
\text { ipilimuab }\end{array}$ \\
CheckMate370 & NCT02574078 & Single arm & $\begin{array}{l}\text { Advanced } \\
\text { NSCLC (ALK) }\end{array}$ & $\begin{array}{l}\text { Nivolumab+ chemo, first line, or SOC Active, not recruiting } \\
\text { (crizotinib) }\end{array}$ \\
\hline
\end{tabular}

immunotherapy exacerbates the frequency and severity of some of the adverse events seen in the clinic, especially the inflammation-driven toxicities, pneumonitis, hepatitis, and pulmonary fibrosis.

The cellular mechanism responsible for less frequent, but more severe TKI-induced adverse events like liver failure and ILD is not defined in the literature. We speculate that it may arise from disruption of normal epithelial tissue homeostasis and an induction of an innate inflammatory response similar to that observed with EGFR inhibitors in epidermal tissues. In support, studies demonstrate that genetic disruption of MET in hepatocytes causes an induction of IL6 ${ }^{[18]}$. Livers from hepatocyte-specific MET knockout mice show an increase in immune cell populations including infiltrating neutrophils, macrophages, and cytotoxic $\mathrm{T}$ cells $^{[19]}$. Inflammatory cytokines also have an established role in hepatocytes, as CXCL10 is found to be expressed by hepatocytes isolated from patients with chronic hepatitis $\mathrm{C}$ infection and are correlated with an increase in lobular inflammation and histological severity ${ }^{[45]}$. Furthermore, the alveolar epithelium is able to contribute to the immune landscape of the lung by generating pro-inflammatory cytokines like CXCL10 and CCL2 when stimulated with IFN $\lambda^{[46]}$. Studies to investigate the effects of gefitinib on airway repair after injury demonstrated that mice treated with gefitinib after naphthalene induced airway injury developed severe pneumonitis driven primarily by infiltrating neutrophils ${ }^{[47,48}$. Bronchial epithelial cells harvested from these mice demonstrated an increase in proinflammatory genes. Taken together, these studies suggest that TKIs induce an innate inflammatory immune response in epithelial tissues where their RTK targets function as dominant signal pathways controlling epithelial homeostasis. Thus, EGFR or MET blockade may contribute to adverse events like liver toxicities and ILD especially when combined with presently deployed anti-PD1/PD-L1 agents.

\section{CONCLUSIONS AND PERSPECTIVES}

Although induction of clinically graded skin toxicities related to an inflammatory phenotype has been classified as an adverse event in cancer patients, we propose that this response represents on-target inhibition of a normal tissue homeostasis program in epithelial cells that is retained in their transformed derivatives. Importantly, this TKI-induced innate immune response may actually represent a therapeutic vulnerability for the tumor. The ability of EGFR and ALK inhibitors to stimulate this response in lung cancers driven by mutant EGFR and ALK is clinically relevant considering their poor responses to immunotherapies deployed as monotherapies. We propose that oncogenic RTKs such as EGFR, ALK, ROS1, and MET act to suppress inflammation mediated by this innate immune response and thereby, actively contribute to immune evasion, a hallmark of cancer. Treatment with TKIs counteract this suppression, thereby "releasing the brake" on inflammatory signaling pathways and allowing for recruitment of effector immune cells and increased antigen presentation [Figure 1]. This provides a mechanism to explain the connection between an inflammatory phenotype and response to TKI. Although this TKI mediated release on inflammatory suppression represents a novel vulnerability that may be capitalized on by treatment with IO, early clinical data indicate that combining TKIs with existing IO exacerbates the frequency and degree of some adverse events, especially pneumonitis, hepatitis, and pulmonary fibrosis. This calls for further preclinical mechanistic studies to fully understand the impact of TKIs on the crosstalk between the TME and cancer cells, as well as the effect on normal epithelial tissue function. 


\section{DECLARATIONS}

\section{Authors' contributions}

Contributed equally to the preparation of the manuscript and figures: Both authors

Read and approved the final manuscript: Both authors

\section{Availability of data and materials}

Not applicable.

\section{Financial support and sponsorship}

None.

\section{Conflicts of interest}

Both authors declared that there are no conflicts of interest.

\section{Ethical approval and consent to participate}

Not applicable.

\section{Consent for publication}

Not applicable.

\section{Copyright}

(c) The Author(s) 2018.

\section{REFERENCES}

1. Siegel RL, Miller KD, Jemal A. Cancer statistics, 2018. CA Cancer J Clin 2018;68:7-30.

2. Politi K, Herbst RS. Lung cancer in the era of precision medicine. Clin Cancer Res 2015;21:2213-20.

3. Vermorken JB, Mesia R, Rivera F, Remenar E, Kawecki A, Rottey S, Erfan J, Zabolotnyy D, Kienzer HR, Cupissol D, Peyrade F, Benasso M, Vynnychenko I, De Raucourt D, Bokemeyer C, Schueler A, Amellal N, Hitt R. Platinum-based chemotherapy plus cetuximab in head and neck cancer. N Engl J Med 2008;359:1116-27.

4. Camidge DR, Pao W, Sequist LV. Acquired resistance to TKIs in solid tumours: learning from lung cancer. Nat Rev Clin Oncol 2014;11:473-81.

5. Dy GK, Adjei AA. Understanding, recognizing, and managing toxicities of targeted anticancer therapies. CA Cancer J Clin 2013;63:249-79.

6. Shaw AT, Kim DW, Nakagawa K, Seto T, Crinó L, Ahn MJ, De Pas T, Besse B, Solomon BJ, Blackhall F, Wu YL, Thomas M, O’Byrne KJ, Moro-Sibilot D, Camidge DR, Mok T, Hirsh V, Riely GJ, Iyer S, Tassell V, Polli A, Wilner KD, Jänne PA. Crizotinib versus chemotherapy in advanced ALK-positive lung cancer. N Engl J Med 2013;368:2385-94.

7. Camidge DR, Bang YJ, Kwak EL, Iafrate AJ, Varella-Garcia M, Fox SB, Riely GJ, Solomon B, Ou SH, Kim DW, Salgia R, Fidias P, Engelman JA, Gandhi L, Jänne PA, Costa DB, Shapiro GI, Lorusso P, Ruffner K, Stephenson P, Tang Y, Wilner K, Clark JW, Shaw AT. Activity and safety of crizotinib in patients with ALK-positive non-small-cell lung cancer: updated results from a phase 1 study. Lancet Oncol 2012;13:1011-9.

8. van Geel RM, Hendrikx JJ, Vahl JE, van Leerdam ME, van den Broek D, Huitema AD, Beijnen JH, Schellens JH, Burgers SA. Crizotinib-induced fatal fulminant liver failure. Lung Cancer 2016;93:17-9.

9. Liu B, Yuan M, Sun Y, Cheng Z, Zhang Z, Hou S, Wang X, Liu J. Incidence and risk of hepatic toxicities associated with anaplastic lymphoma kinase inhibitors in the treatment of non-small-cell lung cancer: a systematic review and meta-analysis. Oncotarget 2018;9:9480-8.

10. Costa RB, Costa RLB, Talamantes SM, Kaplan JB, Bhave MA, Rademaker A, Miller C, Carneiro BA, Mahalingam D, Chae YK. Systematic review and meta-analysis of selected toxicities of approved ALK inhibitors in metastatic non-small cell lung cancer. Oncotarget 2018;9:22137-46.

11. Roskoski R, Jr. The ErbB/HER family of protein-tyrosine kinases and cancer. Pharmacol Res 2014;79:34-74.

12. Lichtenberger BM, Gerber PA, Holcmann M, Buhren BA, Amberg N, Smolle V, Schrumpf H, Boelke E, Ansari P, Mackenzie C, Wollenberg A, Kislat A, Fischer JW, Röck K, Harder J, Schröder JM, Homey B, Sibilia M. Epidermal EGFR controls cutaneous host defense and prevents inflammation. Sci Transl Med 2013;5:199ra11.

13. Mascia F, Lam G, Keith C, Garber C, Steinberg SM, Kohn E, Yuspa SH. Genetic ablation of epidermal EGFR reveals the dynamic origin of adverse effects of anti-EGFR therapy. Sci Transl Med 2013;5:199ra110.

14. Sibilia M, Kroismayr R, Lichtenberger BM, Natarajan A, Hecking M, Holcmann M. The epidermal growth factor receptor: from 
development to tumorigenesis. Differentiation 2007;75:770-87.

15. Suzuki H, Aoshiba K, Yokohori N, Nagai A. Epidermal growth factor receptor tyrosine kinase inhibition augments a murine model of pulmonary fibrosis. Cancer Res 2003;63:5054-9.

16. Sakao S, Tatsumi K. Molecular mechanisms of lung-specific toxicity induced by epidermal growth factor receptor tyrosine kinase inhibitors. Oncol Lett 2012;4:865-7.

17. Trusolino L, Bertotti A, Comoglio PM. MET signalling: principles and functions in development, organ regeneration and cancer. Nat Rev Mol Cell Biol 2010;11:834-48.

18. Borowiak M, Garratt AN, Wüstefeld T, Strehle M, Trautwein C, Birchmeier C. Met provides essential signals for liver regeneration. Proc Natl Acad Sci U S A 2004;101:10608-13.

19. Kroy DC, Schumacher F, Ramadori P, Hatting M, Bergheim I, Gassler N, Boekschoten MV, Müller M, Streetz KL, Trautwein C. Hepatocyte specific deletion of c-Met leads to the development of severe non-alcoholic steatohepatitis in mice. J Hepatol 2014;61:883-90.

20. Brinkmann V, Foroutan H, Sachs M, Weidner KM, Birchmeier W. Hepatocyte growth factor/scatter factor induces a variety of tissuespecific morphogenic programs in epithelial cells. J Cell Biol 1995;131:1573-86.

21. Agero AL, Dusza SW, Benvenuto-Andrade C, Busam KJ, Myskowski P, Halpern AC. Dermatologic side effects associated with the epidermal growth factor receptor inhibitors. J Am Acad Dermatol 2006;55:657-70.

22. Bonner JA, Harari PM, Giralt J, Azarnia N, Shin DM, Cohen RB, Jones CU, Sur R, Raben D, Jassem J, Ove R, Kies MS, Baselga J, Youssoufian H, Amellal N, Rowinsky EK, Ang KK. Radiotherapy plus cetuximab for squamous-cell carcinoma of the head and neck. N Engl J Med 2006;354:567-78.

23. Liu HB, Wu Y, Lv TF, Yao YW, Xiao YY, Yuan DM, Song Y. Skin rash could predict the response to EGFR tyrosine kinase inhibitor and the prognosis for patients with non-small cell lung cancer: a systematic review and meta-analysis. PLoS One 2013;8:e55128.

24. Mohamed MK, Ramalingam S, Lin Y, Gooding W, Belani CP. Skin rash and good performance status predict improved survival with gefitinib in patients with advanced non-small cell lung cancer. Ann Oncol 2005;16:780-5.

25. Petrelli F, Borgonovo K, Cabiddu M, Lonati V, Barni S. Relationship between skin rash and outcome in non-small-cell lung cancer patients treated with anti-EGFR tyrosine kinase inhibitors: a literature-based meta-analysis of 24 trials. Lung Cancer 2012;78:8-15.

26. Pastore S, Lulli D, Girolomoni G. Epidermal growth factor receptor signalling in keratinocyte biology: implications for skin toxicity of tyrosine kinase inhibitors. Arch Toxicol 2014;88:1189-203.

27. Mascia F, Mariani V, Girolomoni G, Pastore S. Blockade of the EGF receptor induces a deranged chemokine expression in keratinocytes leading to enhanced skin inflammation. Am J Pathol 2003;163:303-12.

28. Ivashkiv LB, Donlin LT. Regulation of type I interferon responses. Nat Rev Immunol 2014;14:36-49.

29. Pollack BP, Sapkota B, Cartee TV. Epidermal growth factor receptor inhibition augments the expression of MHC class I and II genes. Clin Cancer Res 2011;17:4400-13.

30. Kersh AE, Sasaki M, Cooper LA, Kissick HT, Pollack BP. Understanding the impact of ErbB activating events and signal transduction on antigen processing and presentation: MHC expression as a model. Front Pharmacol 2016;7:327.

31. Pollack BP. EGFR inhibitors, MHC expression and immune responses: can EGFR inhibitors be used as immune response modifiers? Oncoimmunology 2012;1:71-4.

32. Kumai T, Matsuda Y, Oikawa K, Aoki N, Kimura S, Harabuchi Y, Celis E, Kobayashi H. EGFR inhibitors augment antitumour helper T-cell responses of HER family-specific immunotherapy. Br J Cancer 2013;109:2155-66.

33. Kumai T, Ohkuri T, Nagato T, Matsuda Y, Oikawa K, Aoki N, Kimura S, Celis E, Harabuchi Y, Kobayashi H. Targeting HER-3 to elicit antitumor helper T cells against head and neck squamous cell carcinoma. Sci Rep 2015;5:16280.

34. Natalia J. Gurule NJ, McCoach C, Hinz TK, Marek L, Ryall K, Korpela S, Sisler D, Tan AC, Doebele RC, Heasley LE. Oncogenetargeted agents induce and interferon response in EGFR and EML4-ALK driven lung cancer. In: Cancer Immunotherapy Combinations. Montreal, Canada: Keystone Symposia; 2018.

35. Borghaei H, Paz-Ares L, Horn L, Spigel DR, Steins M, Ready NE, Chow LQ, Vokes EE, Felip E, Holgado E, Barlesi F, Kohlhäufl M, Arrieta O, Burgio MA, Fayette J, Lena H, Poddubskaya E, Gerber DE, Gettinger SN, Rudin CM, Rizvi N, Crinò L, Blumenschein GR Jr, Antonia SJ, Dorange C, Harbison CT, Graf Finckenstein F, Brahmer JR. Nivolumab versus docetaxel in advanced nonsquamous nonsmall-cell lung cancer. N Engl J Med 2015;373:1627-39.

36. Gajewski TF, Corrales L, Williams J, Horton B, Sivan A, Spranger S. Cancer immunotherapy targets based on understanding the T cellinflamed versus non-T cell-inflamed tumor microenvironment. Adv Exp Med Biol 2017;1036:19-31.

37. Spranger S. Mechanisms of tumor escape in the context of the T-cell-inflamed and the non-T-cell-inflamed tumor microenvironment. Int Immunol 2016;28:383-91.

38. Spranger S, Gajewski TF. Tumor-intrinsic oncogene pathways mediating immune avoidance. Oncoimmunology 2015;5:e1086862.

39. Ayers M, Lunceford J, Nebozhyn M, Murphy E, Loboda A, Kaufman DR, Albright A, Cheng JD, Kang SP, Shankaran V, Piha-Paul SA, Yearley J, Seiwert TY, Ribas A, McClanahan TK. IFN-gamma-related mRNA profile predicts clinical response to PD-1 blockade. J Clin Invest 2017;127:2930-40.

40. Moya-Horno I, Viteri S, Karachaliou N, Rosell R. Combination of immunotherapy with targeted therapies in advanced non-small cell lung cancer (NSCLC). Ther Adv Med Oncol 2018;10:1758834017745012.

41. Ahn MJ, Yang HA, Saka H, Ramalingam SS, Goto K, Kim SW, Yang L, Walding AL, Oxnard GR. 136O - Osimertinib combined with durvalumab in EGFR-mutant non-small cell lung cancer: results from the TATTON phase Ib trial. J Thorac Oncol 2016; doi: 10.1016/ S1556-0864(16)30246-5.

42. Rizvi NA, Chow LQM, Borghaei H, Shen Y, Harbison C, Alaparthy S, Chen AC, Gettinger SN. Safety and response with nivolumab 
(anti-PD-1; BMS-936558, ONO-4538) plus erlotinib in patients (Pts) with epidermal growth factor receptor mutant (EGFR MT) advanced non-small cell lung cancer (NSCLC). J Clin Oncol 2014;32:8022.

43. Oshima Y, Tanimoto T, Yuji K, Tojo A. EGFR-TKI-associated interstitial pneumonitis in nivolumab-treated patients with non-small cell lung cancer. JAMA Oncol 2018;4:1112-5.

44. Spigel DR, Reynolds C, Waterhouse D, Garon EB, Chandler J, Babu S, Thurmes P, Spira A, Jotte R, Zhu J, Lin WH, Blumenschein G Jr. Phase $1 / 2$ study of the safety and tolerability of nivolumab plus crizotinib for the first-line treatment of anaplastic lymphoma kinase translocation - positive advanced non-small cell lung cancer (CheckMate 370). J Thorac Oncol 2018;13:682-8.

45. Harvey CE, Post JJ, Palladinetti P, Freeman AJ, Ffrench RA, Kumar RK, Marinos G, Lloyd AR. Expression of the chemokine IP-10 (CXCL10) by hepatocytes in chronic hepatitis $\mathrm{C}$ virus infection correlates with histological severity and lobular inflammation. J Leukoc Biol 2003;74:360-9.

46. Pechkovsky DV, Goldmann T, Ludwig C, Prasse A, Vollmer E, Müller-Quernheim J, Zissel G. CCR2 and CXCR3 agonistic chemokines are differently expressed and regulated in human alveolar epithelial cells type II. Respir Res 2005;6:75.

47. Harada C, Kawaguchi T, Ogata-Suetsugu S, Yamada M, Hamada N, Maeyama T, Souzaki R, Tajiri T, Taguchi T, Kuwano K, Nakanishi Y. EGFR tyrosine kinase inhibition worsens acute lung injury in mice with repairing airway epithelium. Am J Respir Crit Care Med 2011;183:743-51.

48. Mikumo H, Yanagihara T, Hamada N, Harada E, Ogata-Suetsugu S, Ikeda-Harada C, Arimura-Omori M, Suzuki K, Yokoyama T, Nakanishi Y. Neutrophil elastase inhibitor sivelestat ameliorates gefitinib-naphthalene-induced acute pneumonitis in mice. Biochem Biophys Res Commun 2017;486:205-9. 